University of Rhode Island

DigitalCommons@URI

Open Access Master's Theses

1984

\title{
Subject Characteristics as Predictors of Self Change in Smoking
}

Nancy S. Wilcox

University of Rhode Island

Follow this and additional works at: https://digitalcommons.uri.edu/theses

\section{Recommended Citation}

Wilcox, Nancy S., "Subject Characteristics as Predictors of Self Change in Smoking" (1984). Open Access Master's Theses. Paper 1754.

https://digitalcommons.uri.edu/theses/1754

This Thesis is brought to you for free and open access by DigitalCommons@URI. It has been accepted for inclusion in Open Access Master's Theses by an authorized administrator of DigitalCommons@URI. For more information, please contact digitalcommons-group@uri.edu. 
SUBJECT CHARACTERISTICS AS PREDICTORS

OF SELF CHANGE IN SMOKING

BY

NANCY S. WILCOX

A THESIS SUBMITTED IN PARTIAL FULFILLMENT OF THE REQUIREMENTS FOR THE DEGREE OF

MASTER OF ARTS

IN

PSYCHOLOGY

UNIVERSITY OF RHODE ISLAND

1984 


\section{Abstract}

Four categories of subject characteristics that included demographic, smoking history, health history and life experiences variables were investigated as predictors of smokers' success or failure in their self change efforts at smoking cessation over a $\sigma$ month period. Seven hundred and three adult subjects represented five stages of change based on the transtheoretical model: precontemplation, contemplation, action, maintenance and relapse. Two significant multiple discriminant functions were found which predicted movement through each of these stages. Results indicate that the presence of health problems impacted Immotive smokers to move beyond the precontemplation stage. Four smoking history variables, problem duration, daily cigarettes, previous attempts to quit, and pleasure were found to either predict movement through the stages of change or significantly discriminate between smokers in different stages. Overall, a pattern emerged in which the stronger the smoking habit, the less apt the smoker is to quit or maintain a non-smoking status. Demographic findings suggested that smokers with higher incomes and more years of education are more likely than persons of lower socioeconomic levels to be successful in their self change efforts. The non-significant findings of the present investigation are compared with a recent study of smoking behavior change in order to demonstrate the advantages of process-oriented, rather than static variables, for predicting self-change. 


\section{Acknowledgements}

This project began while I was a first semester student in clinical psychology at the University of Rhode Island. I would like to express my appreciation to the members of my thesis committee, James 0. Prochaska, Ph.D, Wayne Velicer, Ph.D. and Jerome Schaffran, Ph.D., as well as several members of the Self-Change Lab, Edward Guadagnoli, Joseph Rossi, Terri Javarey and Elaine Taylor, for their valuable assistance during the past several months.

This work was supported by Grant CA 27821 from the National Cancer Institute. 
Table of Contents

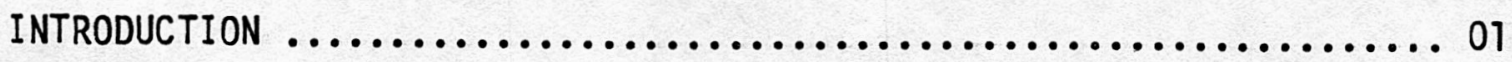

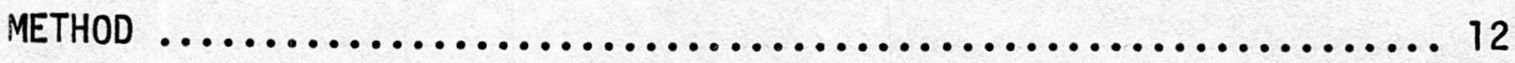

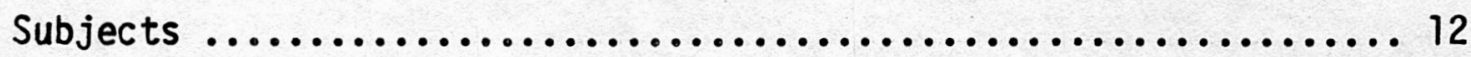

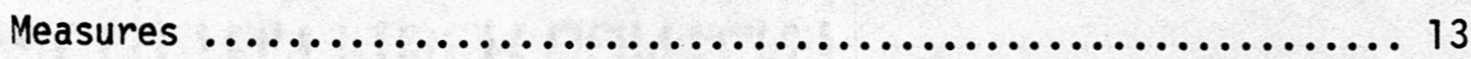

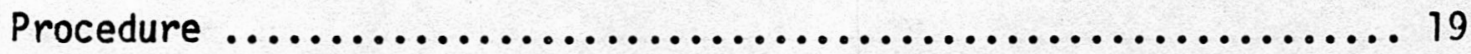

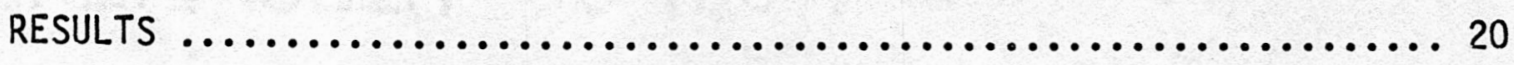

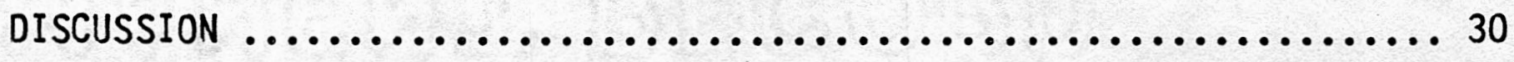




\section{List of Tables}

Table 1 Varimax Rotated Component Patterns for the

Reasons for Smoking Items ......................... 16

Table 2 Means and Standard Deviations of Round I

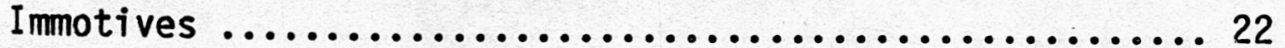

Table 3 Classification Table for Discriminant Function

Round I Immotives

Table 4 Means and Standard Deviations of Round I

Rel apsers ................................. 26

Table 5 Classification Table for Discriminant Function Round I

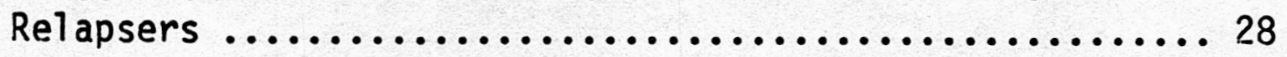




\section{List of Appendixes}

Appendix A Predictor Variables

Appendix B Sample Items

Appendix C Discriminant Analysis Results

Appendix D ANOVA Summary Table for Immotives (Previous Quits)

Appendix $E$ ANOVA Summary Table for Immotives (Pleasure)

Appendix $F \quad$ ANOVA Summary Table for Relapsers (Education)

Appendix G ANOVA Summary Table for Relapsers (Daily Cigarettes)

Appendix $\mathrm{H}$ Newman-Keuls Comparisons on Education for Round I Relapsers

Appendix I Newman-Keuls Comparisons on Daily Cigarettes for Round I Relapsers 
The 1964 Surgeon General's report which linked smoking with an increased risk of cancer influenced many people to change their smoking habits. In 1966, for example, one-half of the men and one-third of the women in the U.S. were cigarette smokers, a total of approximately 50 million smokers. Four years later, there were four and one-half million fewer smokers (Green and Nemzer, 1973). Other findings report that during the period 1964-1974, an estimated 29 million Americans quit smoking (Adult Use of Tobacco, 1975).

Approximately 70 to $80 \%$ of the people who have quit smoking since 1964 have done so on their own without participation in a formalized treatment program. Further, upon questioning, a large majority of smokers indicate that they would not attend a formal program if they were planning to quit (McAlister, 1975). Additionally, of those smokers who ultimately opt to participate in such a program, an average of 75 to $80 \%$ fail to maintain non-smoking status after one year (Hunt and Matarazzo, 1973). Despite these facts and figures, most of the research involving smoking cessation has focused on the development and implementation of formal treatment programs. In recent years, however, investigators (Schwartz, 1976b; McFal1, 1978) have stressed the need for research to focus on individuals who have been able to quit smoking on their own. Recent work in this area has revealed that little is known about the population of smokers and in particular, those persons who have attempted to change their smoking habit without professional assistance.

In an effort to better understand the complexities of smoking, some researchers have attempted to establish a profile of smokers and 
ex-smokers. They have examined a variety of subject characteristics, such as demographics and smoking history information, in order to determine the relationship of such variables to smoking behavior.

On the whole, the existing literature does not consistently identify demographic characteristics as factors which differentiate smokers on the basis of changes in their smoking habits. In 3 out of 7 studies reviewed, for example, no clear relationship between age and smoking behavior change was substantiated (Daughton, 1980; Eisenger, 1972; Straits, 1968). In the four other studies, however, it was found that older persons were more likely to abstain from cigarettes or reduce their consumption level (Bosse, and Rose, 1973; Eisenger, 1971; Ryan, 1973; Hammond \& Percy, 1958). As an example, during a community wide effort by Iowa residents to stop smoking, it was found that long term success was greatest among middle aged men and least among the young (Ryan, 1973). The Mid-town Manhattan study on smoking behavior, which dichotomized respondents into age groups (under 40 and over 40 ), found that male smokers' conversion rate to nonsmoking is higher among younger men (58\%) than among older men (42\%) (Srole \& Fischer, 1973). For the comparable female age groups, the rates of conversion to nonsmoking were not significantly different. In an analysis of data from a national survey of smoking attitudes and behavior, where subjects were interviewed in 1966 and reinterviewed in 1968, it is reported that of the successful abstainers, $43 \%$ were 50 years of age or older and only $15.3 \%$ of the recidivists were in this age category (Eisenger, 1971). One year later, in a follow-up study which classified subjects as either quitters, reducers, no changers or increasers, there was no relationship found between age and smoking 
behavior change (Eisenger, 1972). Because of the wide discrepancies in the available research, it is difficult to assess the significance and utility of age as a predictor of change in smoking habits.

A review of existing literature indicates that the relationship between socioeconomic variables, such as education and income level, and changes in smoking behavior is also unclear. In 2 out of 5 studies which compared education and smoking behavior, higher rates of smoking abstention were related to increased years of education (Adult Use of Tobacco, 1975; Graham and Gibson, 1971). In contrast, other investigations have found that education does not discriminate between changes in smoking behavior (Eisenger, 1971, 1972) and highly educated smokers are not better able to stop smoking than less well educated subjects (Straits, 1968; Eisenger, 1972).

Two studies which relate income and occupation to smoking behavior report that individuals lower on these variables are less apt to quit smoking or be successfut in their efforts at abstention. In a qualitative investigation, however, Meyer et al (1973) report that as blue collar workers increased in number of years smoked, their daily cigarette consumption dropped. It has also been found that white collar workers smoke more on a daily basis as their years as a smoker increase.

Differences in smoking behavior changes, as they relate to socioeconomic status, have also been reported between males and females. Overall, cigarette smoking is more commonly seen among individuals with less education and women in higher income groups. Schuman (1977) points out, for example, that al though more male blue collar workers than white collar workers smoke, the opposite 
relationship holds true for females, with white collar female workers smoking more. Other research reports that professional women are more likely to smoke than their male colleagues (Dicken, 1978). Additionally, Meyer et al (1973) found that women high in years of schooling, occupation, family income and rent are twice as likely to be cigarette smokers as women in the lower end of these scales.

Previous research seems to suggest that, on the whole, smoking history variables, rather than demographic characteristics, are better predictors of changes in smoking behavior. Research to date suggests that the number of years a person has been smoking is a strong indicator of the intensity and extensity of the smoking habit. Several studies (Daughton, 1980; Eisenger, 1971; Graham \& Gibson, 1971; Nelson, 1977; Pomerleau, Adkins, Pertschuk, 1978; Stevens, Greene \& Primavera, 1982) have examined this variable as a prognostic indicator of smoking behavior change. All of them report that the longer a person has been smoking, the less probable it is that he/she will refrain from cigarette smoking. One study (Pomerleau, Adkins, Pertschuk, 1978) found that rate and years smoking were predictive of initial success or failure following participation in weekly treatment sessions but did not significantly predict recidivism during a one year follow-up.

A review of the literature which examines the amount of cigarettes smoked per day reveals that this factor is not as consistent a predictor of smoking behavior change as is the number of years smoked. Graham and Gibson (1971) found, for example, that a direct measure of the number of cigarettes smoked per day does not differ between those who successfully abstain from smoking and those who 
relapse. Similarly, in a recent study, Schachter (1982) reports that light smokers are not more successful at giving up cigarettes than are heavy smokers. He found, for example, that $67.4 \%$ of all light smokers who tried to quit succeeded and $63.3 \%$ of all heavy smokers also succeeded. According to Eiser and Sutton (1978), daily cigarette consumption correlates signficantly with perceived difficulty of giving up smoking and self attributed addiction but shows near-zero correlations with whether subjects attempt to give up or cut down and whether they succeed in their attempt. In contrast, other investigations conclude that as the number of cigarettes smoked per day increases, the rate of quitting decreases (Eisenger, 1972; Nelson, 1977; Pomerleau, Adkins \& Pertschuk, 1978).

In 4 out of 5 studies reviewed, it was found that the smoking habits of significant others, such as spouses, siblings and friends, can influence the smokers' behavior (Eisenger, 1972; Foss, 1973; Graham \& Gibson, 1971; Warnecke, Graham \& Rosentha1, 1978; Stevens, Greene \& Primavera, 1982). The general findings suggest that smokers are more likely to successfully abstain when important persons in their life have either never smoked or have given up the habit (Eisenger, 1972; Graham and Gibson, 1971). Similarly, it has been reported that smokers have more friends who smoke than do persons who have never smoked (Foss, 1973). As Stevens et al. (1982) indicate, the presence of other smokers seems to have a negative influence on the subject's ability to quit smoking. Overall, it appears that significant relationships are an important factor related to smoking behavior change. 
Three studies which examined previous attempts at quitting as a predictor of smoking behavior change were located in the literature. In one such study (Guilford cited in Eisenger, 1972) it is reported that smokers who have failed in their previous attempts to quit are ul timately more successful in quitting than smokers attempting to quit for the first time. On the other hand, in an investigation which used previous failure to abstain from cigarettes for at least one week as a predictor of success or failure in a 10 week treatment program, it was found that the prior experience of having tried and been unable to abstain from cigarettes was associated with failure to break the habit (Jacobs, 1972). Thus, al though in both of these instances, there is evidence to suggest that previous attempts at quitting is related to smoking behavior change, the results are contradictory.

As people attempt to quit smoking, they frequently experience a variety of withdrawal symptoms. Ryan (1973) found, for example, that persons who tried to stop smoking during an anti-smoking campaign noticed changes in their nervous mannerisms and an increase in a number of physical symptoms such as weight gain, feeling restless and tense, blue or depressed, ill-tempered, constipated, and fatigued. In 1971, Graham and Gibson reported that al though successful abstainers experienced increased nervousness, irritability, tension and a sense of loss when they stopped smoking, a considerably larger percentage of recidivists reported such difficulties. In addition, they found that $18 \%$ of those under age 55 who succeeded in their efforts to quit smoking continued to feel a desire to smoke a year or longer after quitting. In a 1982 study of recidivism and self cure of smoking and obesity, Schachter (1982) reported that the process of giving up 
smoking appeared to be relatively painless for light smokers and painful for many heavy smokers. For example, $88.2 \%$ of all light smokers who attempted to quit insisted that there was nothing to it no withdrawal symptoms, no craving, no problems. In contrast, the process was considerably more difficult for heavy smokers. Problems such as marked irritability, sleeplessness, intense cravings, fevers, and cold sweats, were reported by $45.8 \%$ of the heavy smokers. Of the remaining heavy smokers, $25.4 \%$ of them noted minor difficulties and $28.8 \%$ of them reported no problems. In another investigation, Meyer et al (1973) found that the percentage of white collar smokers who have difficulty quitting smoking is higher proportionately than the percentage of blue collar workers who experience difficulty terminating the smoking habit. In particular, there is a greater tendency among white collar smokers to report nervousness, anxiety and a craving for cigarettes when they quit smoking. Conversely, the blue collar workers were more likely to report that they felt nothing or even positive when they gave up cigarettes.

According to Horn (1976), "there is substantial variation in success rates according to the kind of smoker a person is and there are logical reasons to suppose that different kinds of cessation procedures will be more appropriate for some kinds of smokers than for others (p. 96)." In addition, Eisenger (1971) cited as Hochbum's major point that smokers differ in terms of their reasons for smoking and, if effective methods to reduce smoking are to be designed, it is essential to develop a profile of the individual smoker. Foss (1973), for example, found that a significantly large proportion of former smokers did most of their smoking in social situations and in response 
to social influence. He concludes that persons who smoke primarily for social, as opposed to psychological reasons, are much more likely to stop than persons who smoke for other reasons. It has also been reported that "negative-affect smokers" or those who smoke under conditions such as tension, anger, or impatience, are especially likely to resume smoking following abstinence (Pomerleau, Adkins \& Pertschuck, 1978). Overall, it appears that changing smoking behavior is most difficult for persons who use smoking as a mechanism to cope with emotional difficulties.

Within the literature on smoking cessation and behavior change, there is a strong trend to indicate that smokers who experience a direct and serious threat to their health are likely to alter their smoking behavior (Eisenger, 1971; Jacobs, 1972; Foss, 1973). In a retrospective study of 138 ex-smokers and 143 smokers, ranging from 17 to 93 years old, it was found that personal illness helped to decrease smoking and promote quitting (Stevens, Greene, \& Primavera, 1982). In 1980, Daughton cites work by Ball et al. and Dudley et al. which reports that patients with chronic diseases, particularly of the heart and lung, generally have higher rates of smoking cessation than the rest of the population. Additionally, in a discriminant analysis which measured the relationship between smokers' desire to stop smoking and their perceived ability to do so, Eiser (1978) reports that being frightened about health risks was the most important predictor of both wanting and having recently tried to stop smoking, but had no impact on the success or failure of such efforts.

Research regarding the relationship between life events and smoking behavior is limited. In one study, Prochaska and Lapsanski 
(1982) assessed the degree to which positive and negative life changes in the six months prior to participation in a smoking clinic were related to initial smoking cessation and maintenance at a four month follow-up. The results indicated that pre-treatment life changes perceived as positive were associated with failure in a smoking cessation program while life changes perceived as negative were not significantly related to success or failure in the treatment program. According to Prochaska and Lapsanski, these findings support the position of Sarason, Johnson and Seigel (1978), who argue for the utility of differentiating between positive and negative life changes. In an earlier investigation that examined the relationships between smoking, psychological status and stress, Lindethal, Myers and Pepper (1973) found that smokers reported a greater increase in their cigarette smoking when they were experiencing undesirable or catastrophic crises as compared to more desirable life events. These researchers concluded that undesirable occurrences, in contrast to desirable changes, are likely to induce certain kinds of frustration which, in turn, leads to an increase in smoking.

Almost all of the prior research on smoking has focused on individuals who have sought professional assistance to change their behavior. Until recently, little has been known about the population of smokers who have changed their smoking habit on their own. It seems clear that research to date on self-changers has been limited by inadequate models of change. This investigation, however, uses the transtheoretical model to make predictions about changes in smoking habits. The transtheoretical model was developed as a general model of change relevant for understanding the therapy process as well as 
the phenomenon of people changing their problem behaviors without professional assistance (Prochaska, 1979).

During the past five years, the usefulness of this model for studying self change approaches to smoking cessation and modification has received much empirical support (DiClemente \& Prochaska, 1982; Prochaska \& DiClemente, 1982; Prochaska, DiClemente, Velicer \& Zwick, 1981). According to the model, there are 4 basic stages of change: precontemplation, contemplation, action and maintenance. Briefly, individuals in the precontemplation stage do not view their smoking as a problem and have no plans to give up the habit. During the contemplation stage, the smokers are seriously considering changing their behavior. Persons in the action stage have actually instituted some type of changes in their smoking habit. Finally, during maintenance, the individuals are maintaining the new behavior that they have adopted. According to the transtheoretical model, each of these stages is an important part of the sequence that smokers pass through in their efforts to become non-smokers.

By examining the relationships between a variety of subject characteristics and smoking behavior change, this study was designed to increase our knowledge of individuals who change their smoking behavior on their own. Demographic, smoking history, health history and life experiences will be investigated as predictors of which subjects will progress, which will regress and which will remain in the same stage in their self change efforts to modify their smoking habits (see Appendix A). The demographic variables include age, education and income level. The smoking history items include problem duration, most cigarettes ever consumed on a daily basis, daily 
cigarette consumption, smoking status of significant others, previous attempts at quitting, withdrawal symptoms, and reasons for smoking (crutch, stimulation, pleasure, habit, handling). Heal th history assesses the presence or absence of a variety of physical conditions that are associated with the effects of smoking. The life experiences variable measures the impact of stressful and desirable life changes on efforts to stop smoking. By examining such factors and their impact on the self change of smoking behavor, this study contributes to an area of research which has previously been quite meager. While the majority of research on smoking behavior focuses almost exclusively on cessation and recidivism, the current investigation extends beyond outcome alone and examines smokers as they progress along the stages of change.

For the purposes of this investigation, outcome predictions were based on a review of previous research findings. Thus, it was expected that problem duration, smoking status of significant others, pleasure and health would be the best predictors of self change in smoking behavior. Specifically, individuals who are currently experiencing health problems, smoke for reasons of pleasure, have been smoking for shorter periods of time and/or live in a non-smoking environment where neither their spouse or best friends smoke are apt to move into the action and maintenance stages. 


\section{METHOD}

The data used in the current study were collected as part of a larger project and were available through the Self Change Lab at the University of Rhode Island. For this study, those aspects of the data which were relevant for the questions under investigation were selected.

Subjects

There were 703 subjects from Rhode Island and Houston, Texas who volunteered to participate in the study in response to newspaper articles and ads. Basic demographic data on the subjects indicated that they were middle-age and middle-class adults who began smoking as teenagers $(\underline{M}=17$ years $)$. The mean age was 40 and the median 37 years. Of the total sample, $62 \%$ were married, $27 \%$ single, $16.5 \%$ divorced, and $5.8 \%$ separated or widowed; $62.5 \%$ of the subjects were female and 37.5 percent were male. The higher prevalence of females in the study may reflect the tendency of women to be more aware of and concerned about health-related matters than men (Brisoe, 1982). In addition, Hall (cited in Briscoe, 1982) reports that more females than males regard health as an important component of the quality of their lives. This 2 to 1 ratio is consistent with previous research experience which indicates that the proportion of females who volunteer for studies on change is typically twice as high as the number of male volunteers.

of the total sample, $19.3 \%$ had completed high school or less, $41.7 \%$ had attended some college classes, $17.8 \%$ had bachelor degrees, and $19.3 \%$ had some postgraduate education or a graduate degree. Approximately half of the subjects had incomes of less than $\$ 15,000$ 
and $8 \%$ had incomes of more than $\$ 30,000$. Seven hundred and three of these subjects had complete data and were able to be assigned to one of the following 5 groups:

Immotives: These smokers $(N=85)$ represented the precontemplation stage, since they reported that they had no intention of quitting smoking in the next year.

Contemplators: These subjects $(N=141)$ represented the contemplation stage, since they had been smoking regularly for the past year but reported that they were seriously thinking about quitting smoking in the next year.

Recent-quitters: These subjects $(N=104)$ represented the action stage, since they had quit smoking on their own within six months of entering the study.

Long-term quitters: These subjects $(N=178)$ represented the maintenance stage, since they had maintained their non-smoking status for at least six months.

Relapsers: A group of Relapsers $(N=195)$ was included to investigate how individuals use particular change processes after having failed within the past year in their attempt to quit smoking. Measures

Sixteen predictor variables comprised the following four categories of demographics, smoking history, health history and life experiences. All of the variables were assessed by responses to self report items described below (see Appendix B).

Demographics

Age: measured in total number of months

Education: assessed on a seven point scale which ranged from "eight grades or less" to "graduate degree" 
Income: subjects' and spouses' incomes were coded on a seven point scale which ranged from "less than $\$ 5,000$ per year" to "greater than $\$ 30,000$ per year" and then added together for a family income level.

\section{Smoking History}

Problem Duration: the total number of years each subject had been smoking cigarettes regularly, excluding periods of time when they had quit.

Most Cigarettes: the total number of cigarettes typically smoked per day by each subject during the period when they were smoking the most.

Daily Cigarettes: the number of cigarettes per day that were consumed by subjects who were currently smoking. For subjects who smoked, but not on a daily basis, they were asked to indicate how many cigarettes they smoke on a weekly basis. This value was then divided by seven in order to obtain a cigarettes per day value.

Smoking Status of Significant Others: the present use of cigarettes by each subject's spouse, best friend of the opposite sex and best friend of the same sex were rated on a five point scale which ranged from "does not smoke cigarettes" to "smokes 21 or more cigarettes per day". Each spouse and friend were then identified as either a "non-smoker", someone who does not smoke at all or who smokes less than five cigarettes per day or a "smoker", a person who smokes more than five cigaretes per day. This information was then used to assess the subject's environment which was coded as follows:

(1) a non-smoking environment where none of the significant others are smokers. 
(2) a mixed environment where one out of three significant others are smokers and the remaining significant others are non-smokers.

(3) a smoking environment where at least two out of three significant others are classified as smokers.

Previous Quits: total number of previous attempts at quitting was coded on a nine point scale which ranged from "never" to "more than twenty five times".

Withdrawal Symptoms: consists of 17 items which asked each subject to confirm whether they had experienced certain problems, such as weight gain, headaches and anxiety, while they were trying to quit smoking. A numerical value was obtained for this variable by totaling the number of items checked by each subject.

Reasons for Smoking: this scale, based on the smoking typology formulated by Tomkins (1966), consists of 18 items designed to differentiate between various types of smoking. For each item, subjects were asked to respond to the following question: "How often have you felt this way during the last six months in which you were smoking?". The response choices were based on a five point scale ranging from "never" (1) to "always" (5). Prior to performing the discriminant analysis, a principal component analysis was conducted on these items. An $18 \times 18$ matrix of interitem correlations was employed as input for the PCA. The MAP (Velicer, 1976; Zwick and Velicer, 1982) and the Scree (Cattell, 1966) methods were employed to determine the number of components to retain. Based on both rules, five components, which accounted for $62 \%$ of the variance, were retained. The varimax rotated pattern was well defined. Table 1 presents the 18 $i$ tems and the five component patterns. The first component was 
Table 1

Varimax Rotated Component Patterns for

the "Reasons for Smoking" items

Component Loadings

\begin{tabular}{|c|c|c|c|c|c|}
\hline Item & $I$ & II & III & IV & V \\
\hline 1 & & .777 & & & \\
\hline 2 & & & & & .719 \\
\hline 3 & & & .868 & & \\
\hline 4 & .842 & & & & \\
\hline 5 & & & & & \\
\hline 6 & & & & .774 & \\
\hline 7 & & .850 & & & \\
\hline 8 & & & & & .805 \\
\hline 9 & & & .884 & & \\
\hline 10 & .863 & & & & \\
\hline 11 & & & & & \\
\hline 12 & & & & .801 & \\
\hline 13 & & .821 & & & \\
\hline 14 & & & & & .744 \\
\hline 15 & & & .509 & & \\
\hline 16 & .745 & & & & \\
\hline 17 & & & & & \\
\hline 18 & & & & .754 & \\
\hline
\end{tabular}


composed of items such as "I lit up when I was angry, upset or feeling blue" and was labeled "crutch". The second component was composed of items such as "I smoke to give myself a lift or perk myself up". The scale developed from items loading on this component was labeled "stimulation". The third component involved items such as "Smoking cigarettes has been pleasant and relaxing" and was labeled the "pleasure" scale. The fourth component consisted of items such as "I have smoked automatically without even being aware of it". The scale developed from items loading on this component was labeled "habit". The final component was comprised of items such as "Handling a cigarette, lighting up and watching the smoke are a part of the enjoyment of smoking" and was labeled "handling".

Three items were deleted on the basis of the principal component analysis. The remaining fifteen items were employed to form five separate, three-item components, each of which were employed in subsequent analyses. The components are comparable to those described by Ikard, Green and Horn (1969). The only exception is that they identified a sixth component, labeled "Addictive", which did not appear on our PCA. Health History

Each subject was asked whether they had ever been told by a physician that they had certain physical conditions and if so, did they still have the problem. The following fourteen conditions, which have been associated with the effects of smoking, were identified as either life threatening or not life threatening:

Life Threatening

Emphysema

Chronic obstructive pulmonary disease
Not Life Threatening

Asthma Hayfever 
Lung cancer

Other cancer

Heart attack

Heart disease (all kinds)

Hardening of the arteries
Chronic Sinusitis

Chronic bronchitis

Chest Pain (angina)

High blood pressure

ulcers

An assessment of the subject's current health was obtained through the following coding procedure:

(1) = the absence of both life threatening and not life threatening diseases

$(2)=$ the absence of life threatening diseases but the presence of not life threatening diseases

$(3)=$ the presence of life threatening diseases and the absence of not life threatening diseases

$(4)=$ the presence of both life threatening and not life threatening diseases

Life Experiences: the Life Experiences Survey is a 63 item scale designed to measure both positive and negative life changes experienced in the recent past (Sarason, Johnson and Sieger, 1978). Based on the Schedule of Recent Experiences (SRE) (Holmes and Rahe, 1967), it has the advantage of differentiating desirable changes from stressful changes. It has been found to have adequate reliability and higher validity coefficients than the SRE (Sarason, Johnson, and Siegel, 1978). Each item is scored on a Likert scale which ranges from extremely negative to extremely positive. Subjects' responses to each item were totaled in order to obtain a negative intensity score (range of 0 to 189) and a separate positive intensity score (range of 0 to 441 ).

\section{Procedure}

After volunteering for the study in response to newspaper ads, 
subjects were informed of the nature of the research, signed an informed consent form, and were guaranteed anonymity of their responses. Subjects were then mailed a questionnaire, which included the Demographics and Smoking History Questionnaire, the Processes of Change Questionnaire, the Decisional Balance Scale, and the Self-Efficacy Scale. A one-half hour personal interview followed in which participants discussed their smoking experiences and provided a saliva sample for thiocyonate testing to confirm their smoking status. Subjects were reimbursed $\$ 4.00$ for the completed questionnaire and $\$ 4.00$ for the personal inteview. In addition, subjects were eligible to win one of 10 bonus drawings worth $\$ 25$ to $\$ 250$.

Six months after the intial assessment (Round I), a follow-up questionnaire (Round II) was mailed to all subjects. Ninety-two percent of the subjects returned the completed questionnaire. The follow-up questionnaire was identical to the Round I questionnaire except that it eliminated a large portion of the demographics and smoking history items. A review of the smoking literature indicates that six months is one of the standard time intervals used to follow up and assess changes in smoking habits. Consequently, in studying self-changers, a similar time period was selected. 


\section{RESULTS}

An attempt was made to account for differences in smoking status from Round I to Round II within the five groups of subjects described earlier (immotives, contemplators, recent quitters, long term quitters and relapsers). Since over $90 \%$ of the subjects who were long term quitters at the initial assessment remained in the same stage six months later, further analyses for that group were precluded. For each of the remaining four groups, separate step-wise discriminant function analyses using the BMDP7M program and the T.W. Anderson classification analyses (Jennrich \& Sampson, 1981) were performed to predict changes in smoking status over the six month interval. In all cases, the Wilks' likelihood ratio and the Bartlett's V statistic were used to determine statistical significance. Sixteen variables from Round I were entered into each discriminant analysis. These were age, education, income, problem duration, most cigarettes ever consumed on a daily basis, daily cigarette consumption, smoking status of significant others, previous attempts at quitting, the five reasons for smoking (crutch, stimulation, pleasure, habit, and handling), health problems, positive life experiences, and negative life experiences. Uniess otherwise indicated, each of the analyses were performed with all sixteen variables. The results for each of the groups will be considered separately.

In order to interpret the significant discriminant functions, separate univariate analyses of variance were conducted for each of the sixteen predictor variables. The contemplator, recent quitter and relapser groups were viewed as confirmatory since they examined several demographic and smoking history variables which have been 
investigated in previous studies of smoking behavior. In addition, each of these three groups had large sample sizes, thereby increasing the chances for obtaining a statistically significant finding. For these reasons, the .01 level of significance was used for the contemplators, recent quitters and relapsers. In contrast, the alpha level for the immotive groups was set at .05 since no other research has studied this group of smokers. Newman-Keuls tests were performed for the significant one-way ANOVAs on all possible pairwise comparisons to determine which groups differed on the variables. Immotives

For the subjects initially classified as immotives, data was available at the six month follow-up for 85 . They were classified as either immotives $(n=59)$ or changers $(n=26)$. The changer group included membership in one of three other groups (contemplators, recent quitters or relapsers).

The discriminant analysis yielded a single significant function $(\lambda=.32976, \underline{v}=23.227376$, $\underline{d f}=3, \underline{p}<.001)$ (see Appendix $C)$. Three variables were retained in the following order: pleasure, health and problem duration. The function distinguished immotives who remained in the precontemplation stage from those who changed categories on the basis of these three variables. The standardized discriminant function coefficients were as follows: pleasure (.82), health (-.64), problem duration (.51). An examination of the group : means showed that immotives scored higher on pleasure and problem duration while changers scored higher on health (see Table 2), An overall correct classification rate of $74.1 \%$ was achieved when group membership was predicted from this discriminant function (see Table $3)$. The multivariate Omega square value for the discriminant analysis (Tatsuoka, 1970) was .23. 
Table 2

Means and Standard Deviations of Round I Immotives

\begin{tabular}{|c|c|c|c|c|}
\hline \multirow[b]{2}{*}{ Variable } & \multirow[b]{2}{*}{$\underline{M}$} & \multicolumn{2}{|c|}{ Immotives } & \multirow{2}{*}{$\begin{array}{r}\text { Changers } \\
\text { I }\end{array}$} \\
\hline & & $\underline{\sigma}$ & $\underline{M}$ & \\
\hline Age & 469.15 & 148.38 & 418.81 & 125.96 \\
\hline Education & 4.37 & 1.39 & 4.50 & 1.24 \\
\hline Income & 4.61 & 2.01 & 4.77 & 2.03 \\
\hline Problem Duration & 22.80 & 11.92 & 17.31 & 12.02 \\
\hline Most Cigarettes & 32.44 & 16.00 & 26.65 & 12.09 \\
\hline Daily Cigarettes & 28.10 & 14.42 & 22.58 & 8.11 \\
\hline $\begin{array}{l}\text { Smoking Status of } \\
\text { Significant Others }\end{array}$ & 2.10 & .71 & 2.23 & .76 \\
\hline Previous Quits & 2.46 & 1.29 & 3.61 & 2.62 \\
\hline Withdrawal Symptoms & 2.86 & 2.80 & 3.19 & 2.58 \\
\hline Crutch & 10.73 & 2.70 & 11.38 & 2.67 \\
\hline Stimulation & 6.22 & 2.59 & 6.38 & 3.03 \\
\hline Pleasure & 12.15 & 1.64 & 10.42 & 2.40 \\
\hline Habit & 7.19 & 2.22 & 6.62 & 2.73 \\
\hline Handl ing & 6.52 & 2.70 & 5.62 & 2.53 \\
\hline Heal th & 1.29 & .59 & 1.58 & 1.03 \\
\hline $\begin{array}{r}\text { Positive Life } \\
\text { Experiences }\end{array}$ & 19.15 & 19.51 & 19.92 & 30.18 \\
\hline $\begin{array}{r}\text { Negative Life } \\
\text { Experiences }\end{array}$ & 5.39 & 6.15 & 5.92 & 8.40 \\
\hline
\end{tabular}


Table 3

Classification Table for Discriminant Function: Round I Immotives

$\frac{\text { Actual Status }}{\text { At Round I }} \frac{\text { Percent }}{\text { Correct }}$ Number of Cases Classified into Groups

Immotives

Changers

\begin{tabular}{lccc}
\hline Immotives & 78.0 & 46 & 13 \\
Changers & 65.4 & 9 & 17 \\
Total & 74.1 & 55 & 30 \\
\hline
\end{tabular}


The univariate ANOVAS resulted in significant differences between the two groups on the basis of previous quits $(\underline{F}(1,83)=7.470, \underline{p}<$ .001 ) and pleasure $\underline{F}(1,83)=14.936, \underline{p}<.01$ ) (see Appendixes $D \&$ $E$ ). The changers made more attempts to quit smoking (M $=3.61, \underline{\sigma}=$ 2.62) than individuals who remained in the precontemplation stage $(\underline{M}=$ 2.46, $\underline{I}=1.29)$. In addition, the immotives smoked more for reasons of pleasure $(\underline{M}=12.15, \underline{\sigma}=1.64)$ than did the changers $(\underline{M}=10.42$, I = 2.40). F max tests for homogeneity of variance, performed for both of the univariate ANOVAs, were not significant: $E_{\max }$ for previous quits $(2,34)=2.03$, n.s.; $F_{\max }$ for pleasure $(2,34)=1.47$, n.s.). Omega square values were .07 for previous quits and .14 for pleasure.

The frequency values for previous quits were examined in order to determine the proportion of subjects, if any, who had never made a previous attempt to quit smoking. According to the data, $93 \%$ of the subjects had made at least one attempt to quit smoking prior to participation in the study.

Contemplators

A discriminant analysis was performed on four groups of subjects, all of whom had been classified at Round I as contemplators. The groups consisted of those who at Round II had become recent quitters $(n=10)$, relapsers $(n=37)$, immotives $(n=14)$ or those who remained contemplators $(n=80)$. None of the variables were found to be predicters of change for these four groups. In addition, the univariate ANOVAs did not reveal any significant differences among the groups.

Recent Quitters

For the subjects initially classified as recent quitters, data was 
available at the six month follow-up for 104. They were classified in one of three groups: long term quitters $(n=55)$, recent quitters $(n=16)$ or relapsers $(n=33)$. All of the variables described above were entered into the analysis with the exception of daily cigarettes since by the nature of their recent quitter status, these subjects were not smoking at Round I. None of the variables emerged as predictors of change for these groups. Also, there were no significant differences among the three groups on the univariate ANOVAS.

Relapsers

Changes in smoking status from Round I to Round II among the 195 subjects originally classified as relapsers were investigated via stepwise discriminant analysis conducted on the following four groups: immotives $(n=21)$, contemplators $(n=39)$, recent quitters $(n=16)$ or relapsers $(n=119)$.

The discriminant analysis yielded only one significant function $(\lambda$ $=.17471, \underline{v}=31.890051, \underline{d f}=6, p<.001$ ) (see Appendix C). Two variables were obtained in the following order: daily cigarettes and income. The function distinguished relapsers who moved into the precontemplation or contemplation stages from those who either remained as relapsers or took action. The standardized discriminant function coefficients were .89 for daily cigarettes and -.62 for income. An examination of the group means showed that relapsers and recent quitters scored higher on income while immotives and contemplators scored higher on daily cigarettes (see Table 4). An overall correct classification rate of $43.6 \%$ was achieved when group membership was predicted from this discriminant function (see table 5). The multivariate Omega square value for the discriminant analysis (Tatsuoka, 1970) was .14. 


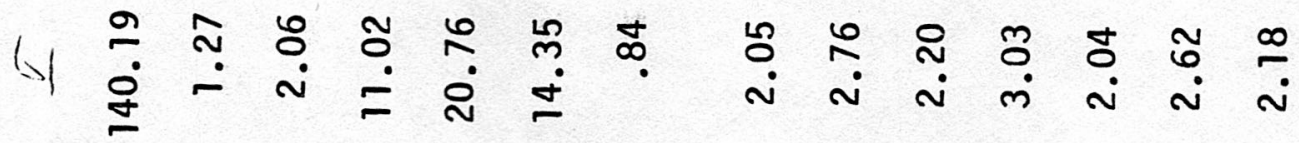

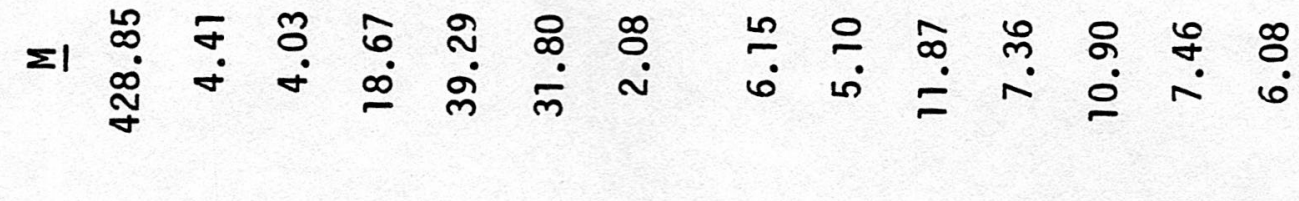

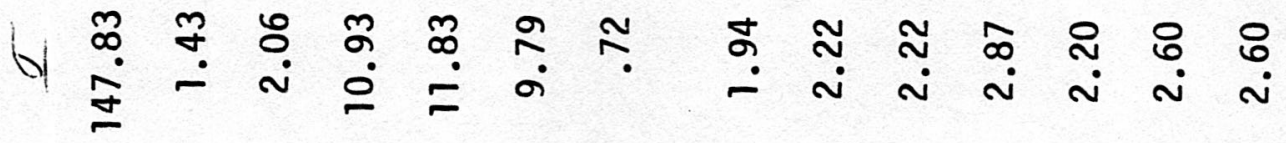

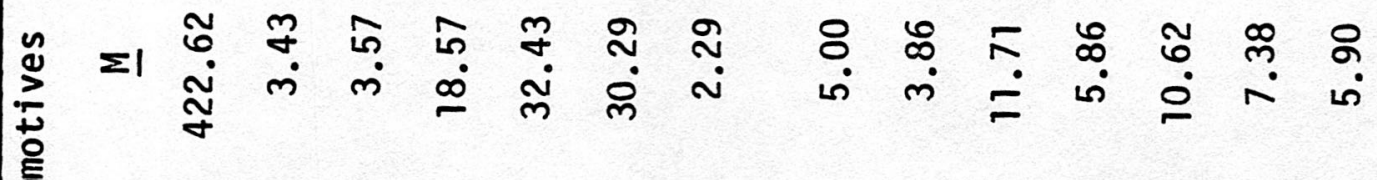

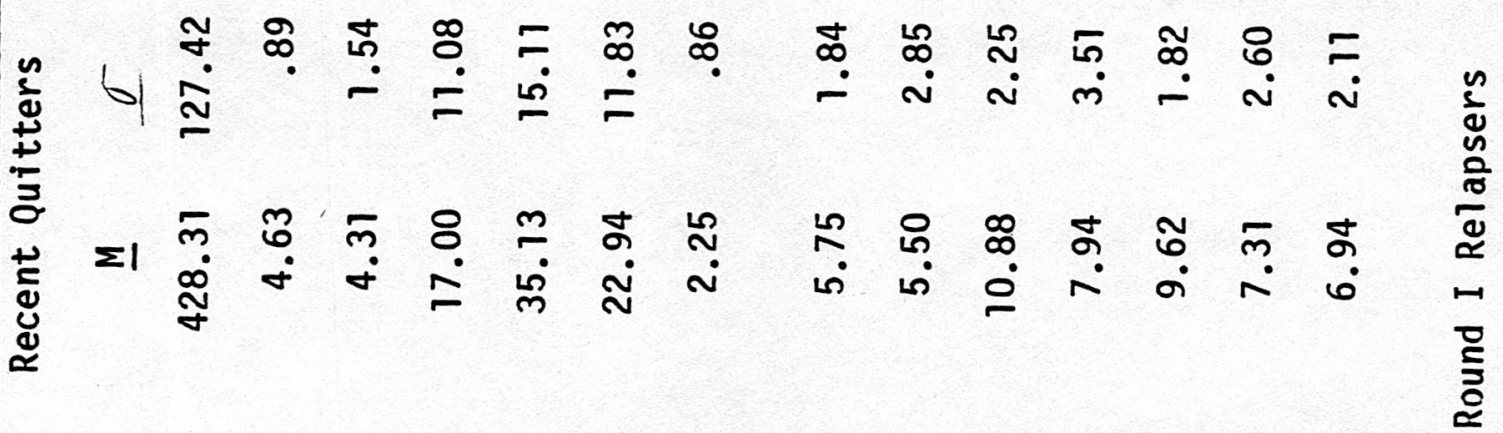
苅

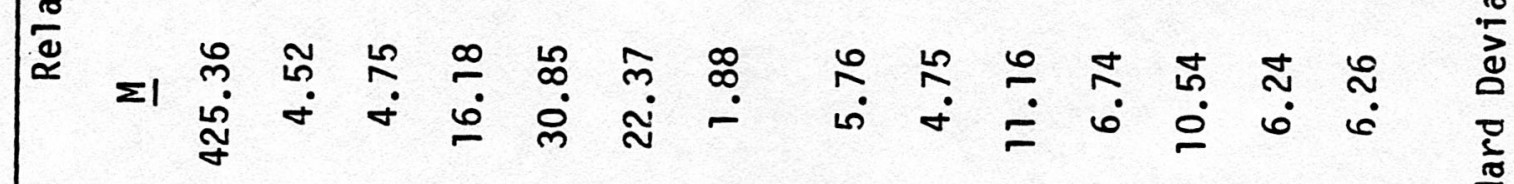

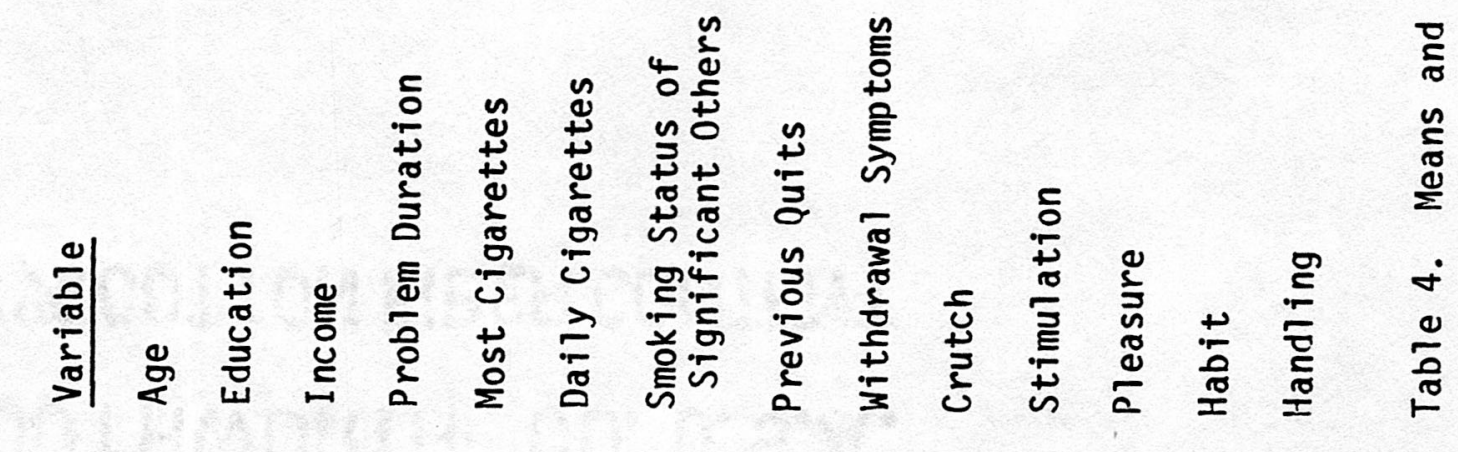




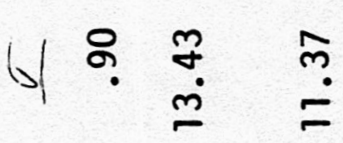

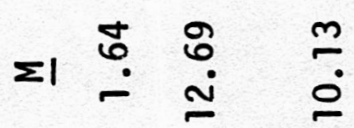

$$
\begin{aligned}
& \text { () }
\end{aligned}
$$

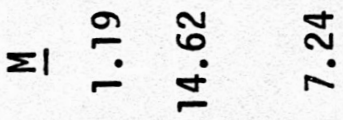

$$
\begin{aligned}
& \text { b) } \underset{\sim}{\stackrel{n}{\pi}}
\end{aligned}
$$

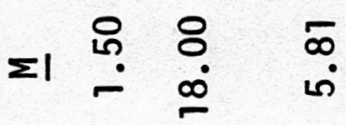

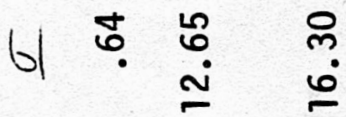

$$
\begin{aligned}
& =1 \stackrel{m}{m} \stackrel{\infty}{m} \stackrel{\sim}{\infty}
\end{aligned}
$$

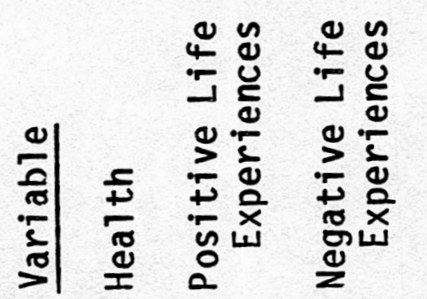




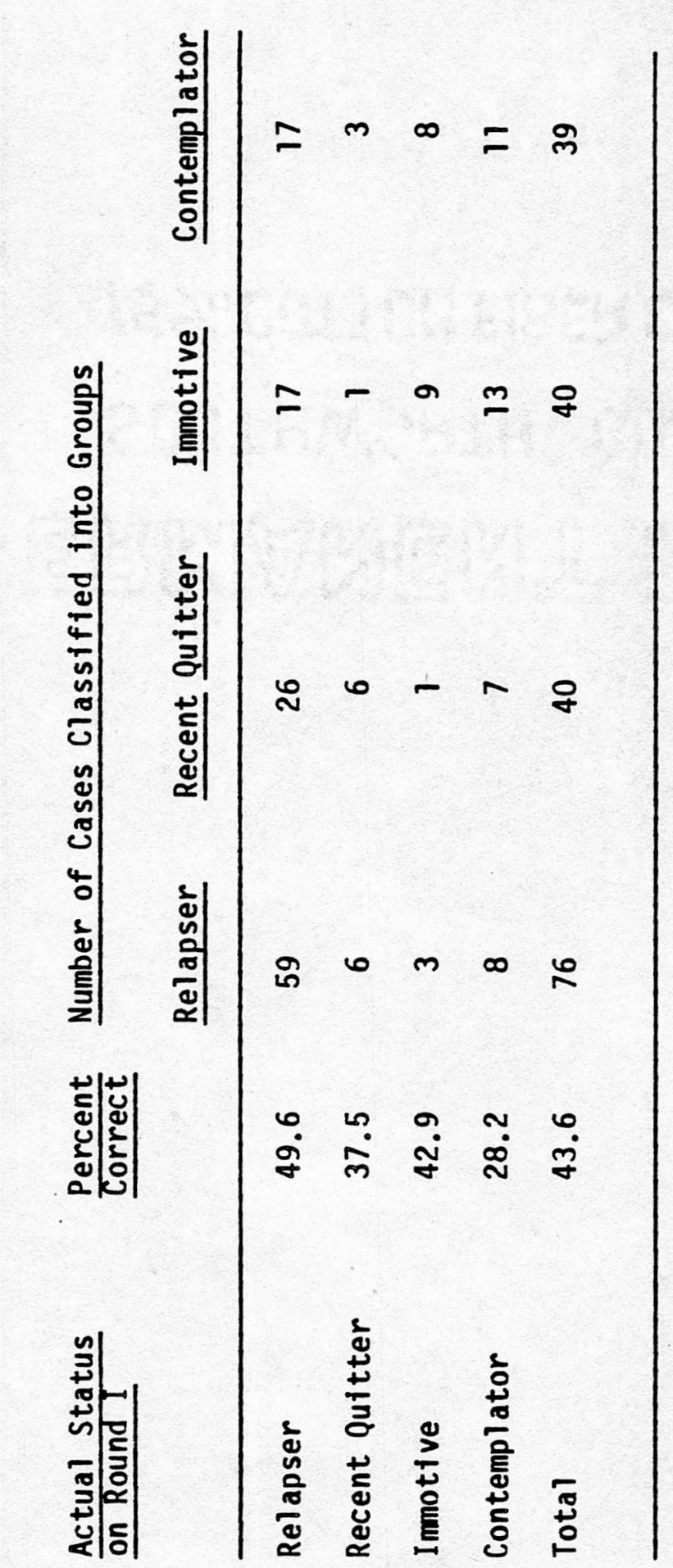

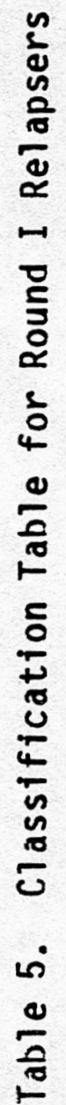


The univariate ANOVAs resulted in significant differences among the four groups on the basis of education $(\underline{F}(3,191)=4.14, \underline{p}<.01)$ and daily cigarettes $(\underline{F}(3,191)=7.07, \underline{\mathrm{p}}<.001$ ) (see Appendixes $F$ \& G). Of the four groups, the recent quitters had the most years of education ( $\underline{M}=4.63, \underline{\sigma}=.89$ ) while subjects in the precontemplation stage were the least educated $(\underline{M}=3.43, \underline{I}=1.43)$. Al so, it was found that the contemplators smoked more cigarettes per day $(M=$ $31.80,-14.35$ ) than subjects in any of the other groups. $F_{\max }$ tests for homogeneity of variance, performed for both of the univariate ANOVAs were not significant: $\left(F_{\max }\right.$ for daily cigarettes $(4,25)=1.47 ; F_{\max }$ for Education $(4,25)=1.62$, n.s). The Omega square values were .05 for education and .09 for daily cigarettes.

Significant differences between precontemplators and each of the remaining groups on the basis of education were found using the Newman-Keuls procedure (see Appendix $H$ ). The Newman-Keuls test did not reveal any significant differences among the groups on the basis of daily cigarettes (see Appendix I). 


\section{Discussion}

This study investigated sixteen variables, consisting of demographic, smoking history, health history, and life experiences items, as predictors of self change in smoking behavior. Of the sixteen variables, the following six demonstrated statistical significance: education, income, problem duration, daily cigarettes, pleasure, and health. Three of the current findings are in agreement with the original predictions that health, problem duration and pleasure would discriminate between groups of smokers. The prediction based on smoking status of significant others did not demonstrate statistical significance. Overal1, these results confirm the original hypothesis that certain subject characteristics are predictors of self change in smoking.

The first function discriminated immotives who remained in the precontemplation stage from those people who moved to another stage of change on the basis of health, smoking for pleasure and problem duration. It was found that, when faced with heal th problems, immotives are likely to progress beyond the precontemplation stage. This finding is in agreement with Prochaska and DiClemente's (personal communication, November 21,1983 ) predictions that environmental or developmental occurrences such as health problems, can lead to serious contemplation of change. It is not clear from the available data, however, whether the presence of health problems is sufficient to move a smoker into an action or maintenance stage.

Previous research, which has examined the impacts of health on smoking habits, reports that serious health threats lead to changes in smoking habits (Eisenger, 1971; Foss, 1973; Jacobs, 1972). The 
results of the current investigation indicate that the health problems did not need to be life threatening in order to influence the smoker. It is important to recognize, however, that while other studies refer to actual changes in behavior, our finding suggests that health problems lead to changes in a smoker's intentions about their habit. From a transtheoretical perspective, modification of one's intentions is the critical first step in changing one's behavior.

The first function al so indicates that the longer a person has been smoking, the less apt they are to consider modifying their habit or to actually take action. This finding is consistent with earlier research which suggests that it is difficult for persons to change a smoking habit that they have been maintaining for several years (Daughton, 1980; Eisenger, 1981; Graham \& Gibson, 1971; Nelson, 1977; Pomerlean, Adkins \& Perschuk, 1978).

In a recent study based on Janis and Mann's (1977) model of decision-making, Velicer, DiClemente, \& Prochaska (in press) investigated the positive (Pros) and negative (Cons) aspects of smoking as predictors of smoking status. They reported that the Pros of smoking clearly outweigh the Cons for individuals who continue to smoke and have no plans to change their behavior in the near future. The present finding that immotives smoke more for reasons of pleasure than individuals in other stages is consistent with the results of Velicer et al. and seems to reflect the higher level of enjoyment and value that precontemplators place on cigarettes.

The first ANOVA indicated that there was a significant difference in the number of previous quits between those who remained in precontemplation and those who moved to another stage. Since over $93 \%$ 
of the subjects in the study have made at least one attempt to quit smoking, the difference in the number of previous quits is not simply because the immotives had never tried to stop smoking. Research on the transtheoretical model (Di Clemente \& Prochaska, 1982) reports that most smokers pass through the stages of change an average of three times before they successfully abstain from cigarettes. Upon relapse, approximately $80-85 \%$ of these smokers return to the contemplation stage where they prepare for another attempt at quitting. The remaining $15-20 \%$ of smokers move into the precontemplation stage following a relapse. In light of this information, the current results may reflect a group of smokers who, upon relapse, become so discouraged about their failure that they return to the precontemplation stage. In contrast, the remaining smokers, although they may take a short break from abstention, seem to move into the contemplation stage and begin to prepare for another quit date.

According to the results of the second discriminant function, people who were relapsers at Round I and who remained in the relapser stage or took action, smoked fewer cigarettes per day than people who, upon relapse, moved into the contemplation and precontemplation stages. This finding suggests that of those who have tried to quit but have failed, the ones who are most apt to try to quit again are the lighter smokers. In contrast, heavy smokers who try to quit but fail are likely to move into a non-action stage. Eiser and Sutton (1978) report that daily cigarette consumption is significantly correlated with perceived difficulty of giving up and self-attributed addiction. They argue that "seeing oneself as unable to give up 
provides both a subjectively valid explanation for past failures and an excuse for continuing to smoke" (p. 106). Hence, it seems that the experience of failure influences the smokers beliefs about their problem. Having failed, smokers are apt to perceive themselves as addicted to cigarettes and hence, experience the feeling that they are not capable of controlling their smoking behavior. Another possible explanation for this finding is that since heavy smokers experience more withdrawal systems than light smokers (Schachter, 1982), they are reluctant to repeat the experience of quitting.

With the exception of health, all of the significant findings mentioned thus far are reflective of the subjects' smoking history. The question arises as to how problem duration, daily cigarettes, previous quits and pleasure are related to each other. Is there a common factor that underlies this group of smoking history variables? Problem duration and daily cigarettes seem to reflect the intensity of a smoker's habit. Similarly, the amount of pleasure people derive from smoking cigarettes, as well as the number of times they have attempted to quit, appear to be indicative of the importance of cigarette smoking in their life. Thus, al though researchers have tended to view variables such as these as separate predictors of smoking status, they may actually represent the same underlying factor, strength of habit. Recently, Velicer, Prochaska and DiClemente (personal communication, September 21,1983 ) have begun to employ structural equation analyses to test whether variables such as problem duration, daily cigarettes, previous quits and pleasure are external manifestations of the latent variable, strength of habit. 
Both the discriminant analysis and univariate ANOVA for the Round I relapsers reflect differences based on socioeconomic status. It was found that persons with lower incomes and fewer years of education move into a non-action stage after having relapsed in their abstention efforts. In contrast, individuals at the higher income and educational levels are more likely, following a relapse, to try again to abstain from cigarettes. Although there is some evidence in previous research to suggest that individuals at the higher socioeconomic levels tend to be more successful in their efforts to stop smoking (Adult use of Tobacco, 1975; Graham \& Gibson, 1971), these findings are not consistent. In the psychotherapy outcome literature, it has generally been reported that continuation in therapy is most often seen in individuals of the higher social classes and education levels. Although the reason for such findings are not clear, one possible explanation is that these results reflect a willingness on the part of people in the higher socioeconomic levels to persist in their change efforts. In terms of the current findings, there is clearly a tendency for smokers from the higher educational and income levels to continue in their abstention efforts in spite of their failed attempts.

Within the current investigation, the Omega square values, or the proportion of variance accounted for by any single subject characteristic, ranged from .06 to .14. Rosenthal and Rubin (1982) have proposed the Binomial Effect Size Display (BESD) as an al ternative way to interpret such findings. They developed this general purpose display of magnitude of experimental design in response to the tendency by behavioral researchers to underestimate 
the importance of statistical findings that are based on low $r^{2}$ values. The BESD is primarily intended to assess changes in success rate which result from treatment inteventions. In terms of the current findings, however, the Omega square value of .14 for pleasure is of the same magnitude as a BESD shift in success rate from . 30 to .70. Even the smallest Omega square value of .05 for education is equivalent to a BESD increase in success rate from .35 to .62 . Suppose, for example, our success rate with smokers was $35 \%$ and we were able to control a variable that had an Omega square value of .05. Theoretically, then, according to the BESD, it would be possible to increase our success rate to $62 \%$. Of course, this assumes that we are able to control the particular variable under consideration. Unfortunately, however, static variables are often not under the control of either the smoker or a therapist.

In the past, there seems to have been an assumption that, in order to further our knowledge and understanding of smoking, it was essential to investigate static variables. Ryan, (1973), for example, stated that "any attempt to explain smoking behavior which ignores demographic variables (such as age, gender, income and socioeconomic $c$ lass) and personality types is a deceptive oversimplification ( $p$. 240)." A decade later, researchers (Stevens, Greene \& Primavera, 1982) still cling to the notion that a combination of static variables, such as social, demographic, environmental and physical factors can be used to differentiate smokers from ex-smokers.

Another reason why many researchers have continued to focus on static variables is a result of the belief that it is not possible to study process variables in the natural environment. Recently, 
however, process variables, such as self efficacy, Decisional Balance and the ten processes of change of the transtheoretical model have been shown to predict changes in smoking behavior in the natural environment over a six month period (Prochaska, DiClemente, Ginpil, Norcross \& Velicer, unpublished manuscript). It was found, for example, that self efficacy is a strong contributor of change for both contemplation to action and action to maintenance. The Pros and Cons of the Decisional Balance Scale were shown to be predictors of change in the precontemplation and contemplation stages. In addition, the transtheoretical model change processes oriented toward enviromental events, such as dramatic relief and social liberation, tended to predict failure or no progress while more experientially-oriented processes predicted progress.

Several static variables, such as health, reasons for smoking and the number of cigarettes smoked on a daily basis are similar to process-oriented variables in that they are amenable to change through either self control or professional intervention. It is possible, for example, that a clinician may successfully intervene to help a precontemplator become more aware of their high risks for health problems or encourage a contemplator to gradually decrease the number of cigarettes that he or she smokes each day. Although professionals may be able to use their knowledge of static variables to impact a person's smoking habit, researchers are encouraged to further investigate the processes related to changes in smoking behavior.

It should be noted that while this study examined change over a six month period, other investigations have examined smoking behavior over a lifetime. It is possible that, given a time period of greater 
than six months, more of the static variables would have emerged as predictors of changes in smoking behavior. Interestingly, however, the self-efficacy, Decisional Balance and ten processes of change were able to make more accurate predictions than the static variables after six months. It is noteworthy that as professionals, we are generally limited to short time spans, rather than several years, in which to intervene.

Al though the current investigation has focused on changes in smoking behavior, the results have important implications for other areas of change. In therapy research, for example, a great deal of attention has frequently been paid to client characteristics such as the ones employed in the present study. Both the smoking and therapy literature represent areas of research which have tended to regard outcome as the ultimate measure of change. Viewing people exclusively as either smokers or ex-smokers or therapy successes versus therapy failures, however, is an oversimplication of the issues underlying change. By focusing on the stages of change of the transtheoretical model, the progress made by a precontemplator who has moved into the contemplation stage becomes as significant as the progress of a person who has moved from contemplation to action. Previously, the changes made by the precontemplator were likely to have been overlooked.

The results of the current investigation may also be useful for understanding other problem areas such as weight and alcohol. It is possible that information about a client's problem history or habit strength, variables which emerged in this study as the most frequent predictors of change, could be used to help people change other problematic behaviors. We may find that people with weight and 
alcohol problems, like the immotive smokers in the present study, require the presence of an external imposition, such as a health problem, before they move beyond the precontemplation stage. Certainly, future investigations of the critical elements which initiate contemplation and action will contribute significantly to our understanding of change. 


\section{References}

Adult Use of Tobacco, 1975 (1976). (U.S. Department of Health, Education and Welfare Publications). Washington, D.C.: U.S. Government Printing Office, 1976.

Bosse, R., and Rose, C.L. (1973). Age and interpersonal factors in smoking cessation. Journal of Health and Social Behavior, 1973, $14(4), 381-387$.

Catte11, R.B. (1966). The scree test for the number of factors. Multivariate Behavioral Research, 1, 245-276.

Briscoe, M. (1982). Sex differences in psychological well-being. Psychological Medicine Monographs, (1), 1-46. Daughton, D.M., Fix, A.J., Kass, I. \& Patil, K.D (1980). Smoking cessation among patients with chronic obstructive pulmonary disease (COPD). Addictive Behaviors, $\underline{5}, 125-128$.

Dicken, C. (1978). Sex roles, smoking and smoking cessation. Journal of Health and Social Behavior, 19, (3), 324-334. DiClemente, C.C. \& Prochaska, J.0. (1982). Self-change and therapy change in smoking behavior: A comparison of processes of change of cessation and maintenance. Addictive Behaviors, $\underline{7}, 133-142$. Eisenger, R.A. (1971). Psychosocial predictors of smoking recidivism. Journal of Health and Social Behavior, 12, 355-362. Eisenger, R.A. (1972). Psychosocial predictors of smoking behavior change. Social Science and Medicine, $\underline{6}, 137-144$. Eiser, R.J. \& Sutton, S.R. (1978). "Consonant" and "Dissonant" smokers and the self- attribution of addiction. Addictive Behaviors, $\underline{3}, 99-106$.

Foss, R. (1973). Personality, social influence and cigarette smoking. Journal of Health and Social Behavior, 14, 279-286. 
Graham, S., \& Gibson, R.W. (1971). Cessation of patterned behavior: withdrawal from smoking. Social Science and Medicine, 5 , 319-337. Green, D.E. \& Nemzer, D.E. (1973). Changes in cigarette smoking by women - an analysis, 1966 and 1970. Health Services Reports, 88, (7), 637-636.

Hammond, E.C. \& Percy, C. (1958). Ex-smokers. New York State Journal of Medicine, $58,1958$.

Holmes, T.H. Rahe, R.H. (1967). The social readjustment rating scale. Journal of Psychosomatic Research, 11, 213-218.

Horn, D. (1976). A model for the study of personal choice health behavior. Journal of Health Education, 19, (2), 89-98. Hunt, W.A. \& Matarazzo, J.D. (1973). Three years later: recent developments in the experimental modification of smoking behavior. Journal of Abnormal Psychology, 81, (2), 107-114. Ikard, F.F.. Green, D.E. \& Horn, D. (1969). A scale to differentiate between types of smoking as related to the management of affect. The International Journal of the Addictions, 4 , (4), 649-659. Jacobs, M.A. (1972). The addictive personality: prediction of success in a smoking withdrawal program. Psychosomatic Medicine, 34, (1), 30-38.

Janis, I.L., \& Mann, L. (1977). Decision making : A psychological analysis of conflict choice and committment. New York : Free Press.

Jennrich, R. \& Sampson. P. (1981). Stepwise Discriminant Analysis. In W.J.Dixon, (Ed.), BMDP Statistical Software 1981. Berkeley : California.

Lindetha1, J.J., Myers, J.K., \& Pepper, M.P. (1972). Smoking, psychological status and stress. Social Science and Medicine, $\underline{6}$, 583-591. 
McAlister, A. (1975). Helping people quit smoking: current progress. In A.M. Enelow and J.B. Henderson, (Eds.), Applying Behavioral Science to Cardiovascular Risk. New York: American Heart Association.

McFall, R.M. (1971). Smoking cessation research. Journal of Consulting and Clinical Psychology, 37, 80-86.

Meyer, A.S., Freidman, L.N., \& Lazarsfeld, P.F. (1973). Motivational conflict sengendered by the on-going discussion of cigarette smoking. In W.L. Dunn, (Ed.), Smoking Behavior: Motives and Incentives. Washington, D.C., V.H. Winston and Sons.

Nelson, S.K. (1977). Behavioral control of smoking with combined procedures. Psychological Reports, 40, 191-196.

Pomerleau, O., Adkins, D., \& Pertschuk, M. (1978). Predictors of outcome and recidivism in smoking cessation treatment. Addictive Behaviors, $\underline{3},(2), 65-70$.

Prochaska, J.0. (1979). Systems of Psychotherapy: A Transtheoretical Analysis. Homewood, Illinois: Dorsey Press,. Prochaska, J.0., DiClemente, C.C. (1982). Transtheoretical Therapy:

Toward a more integrative model of change. Psychotherapy:

theory, research and practice, 19, 276-288.

Prochaska, J.0., DiClemente, C.C., Ginpil, S., Norcross, J.C., \&

Velicer. W.F. (1982). Self-change approaches to smoking cessation: Change Processes, decisional blance, and self-efficacy as predictors. Unpublished manuscript.

Prochaska, J.0., DiClemente, C.C., Velicer, W.F., Zwick, W.R. (1981). Measuring the processes of change used in smoking cessation. Paper presented at the Annual Meeting of the International Council of Psychologists, Los Angeles, CA. 
Prochaska, J.O. \& Lapsanski, D.V. (1982). Life changes and smoking cessation and maintenance : A preliminary report. Psychological Reports, 50, 609-610.

Rosenthal, R., \& Rubin, D.B. (1982). A simple general purpose display of magnitude of experimental effect. Journal of Eduucational Psychol ogy, 74, (2), 166-169.

Ryan, F.J. (1973). Cold Turkey in Greenfield, Iowa: A follow-up study. In W.L. Dunn (Ed.), Smoking Behavior: Motives and Incentives. Washington, D.C., V.H. Winston and Sons.

Sarason, I.G., Johnson, J.H. \& Siegel, J.M. (1978). Assessing the impact oflife change : Development of the life experiences survey. Journal of Consulting and Clinical Psychology, $\underline{46}$, 937-946.

Schachter, S. (1982). Recidivism and self-cure of smoking and obesity. American Psychologist, 37, (4), 436-444.

Schwartz, J.L. (1975). Status of cessation control programs in Europe and North America. In J. Steinfeld, W. Griffiths, K. Ball and R.M. Taylor (Eds.). Proceedings of the Third World Conference on Smoking and Health, (DHEW Publication No. (NIH) 77-1413). Washington, D.C.: U.S. Government Printing Office, 1977 (b). Shuman, L.M. (1977). Patterns of smoking behavior. In M.W. Jarvik, J.W. Cullen, E.R. Gritz, T.M. Vogt, \& L.J. West, Research on Smoking Behavior (NIDA Research Monograph 17, DHEW Publication No. (ADM) 78-581). Washington, D.C.: U.S. Government Printing Office, 1977.

Srole, L., \& Fischer, A.K. (1973). Smoking behavior 1953 and 1970:

The midtown Manhattan study. In W.L. Dunn, (Ed.), Smoking Behavior Motives and Incentives. Washington, iJ.C., V.H. Winston and Sons, $255-265$. 
Stevens, P.A., Greene, J.G., \& Primavera, L.H. (1982). Predicting successful smoking cessation. The Journal of Social Psychol ogy, $118,235-241$.

Straits, B.C. (1968). Discriminating between ex-smokers, smokers not wishing to quit, and smokers who fail or succeed in treatment. In J.L. Schwartz and M. Dubitzky, Psycho-Social Factors Involved in Cigarette Smoking and Cessation. Berkeley, California: Institute for Health Research.

Tatsuoka, M.M. (1970). Discriminant analysis: The study of group differences. In Selected Topics in Advanced Statistics, (6), Institute for Personality and Ability Testing.

Tomkins, S.S. (1966). Psychological model for smoking behavior. American Journal of Public Health, 56, (12) Part II, 17-20.

Velicer, W.F. (1976). Determining the number of components from the matrix of partial correlations. Psychometrika, 41, 321-327. Velicer, W.F., Declemente, C.C., \& Prochaska, J.O. (in press). A dicisional balance measure for assessing and predicting smoking status. Journal of Personality and Social Psychology Warnecke, R.B., Graham, S., Rosenthal, S.F. Social and psychological correlates of smoking behavior among black women. Journal of Health and Social Behavior. 1978 December, Vol. 19(4) 397-410. Zwick, W.R. \& Velicer, W.F. (1982). Factors influencing four rules for determining the number of components to retain. Multivariate Behavioral Research, 17, 253-269. 


\section{Appendix A}

\section{PREDICTOR VARIABLES}

Demographics:

Age

Education

Income

Smoking History:

Problem Duration

Most Cigarettes ever consumed on a daily basis

Daily cigarette consumption

Smoking status of significant others

Previous attempts at quitting

Withdrawal symptoms

Reasons for smoking: Crutch

Stimulation

Pleasure

Habit

Handling

Heal th History:

Presence and/or absence of life threatening and/or not life threatening diseases.

\section{Life Experiences:}

Positive life experiences

Negative life experiences 
Occured in past 6 months

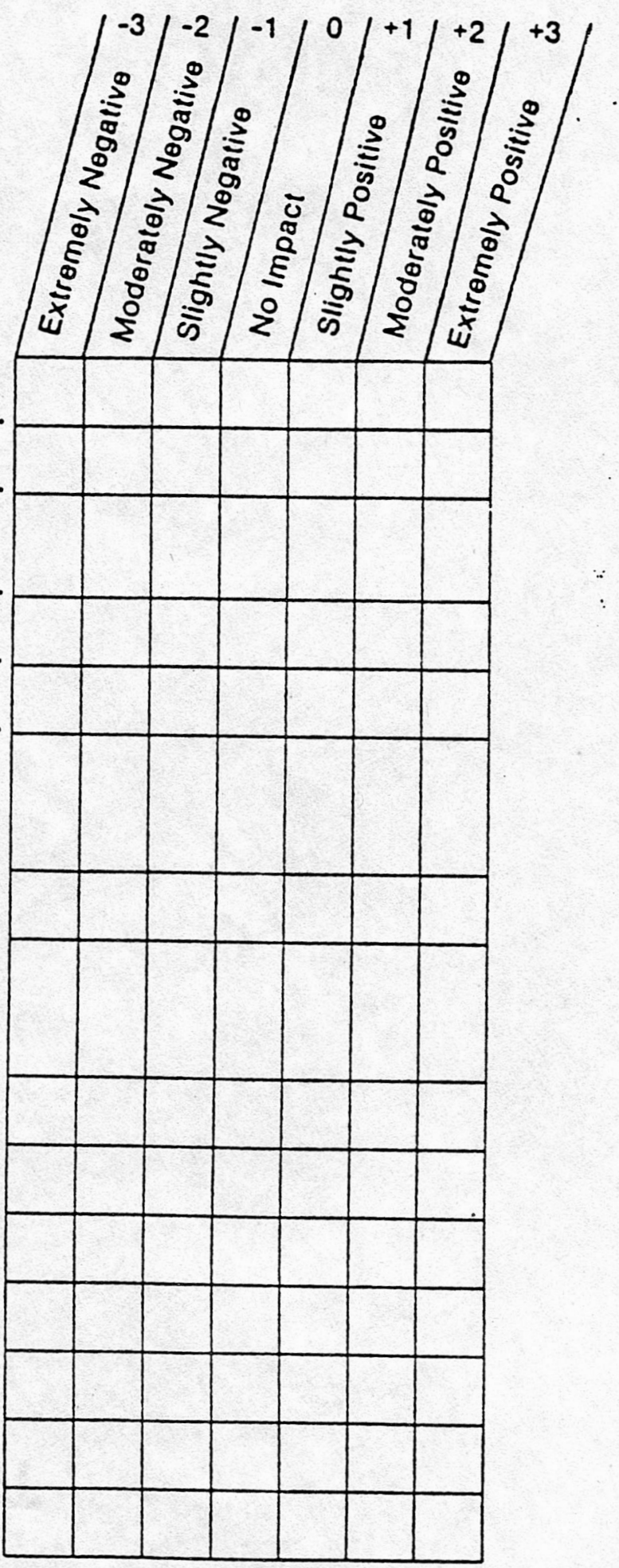


16. Sexual difficulties

17. Trouble with employer (in danger of losing job. being suspended, demoted, etc.)

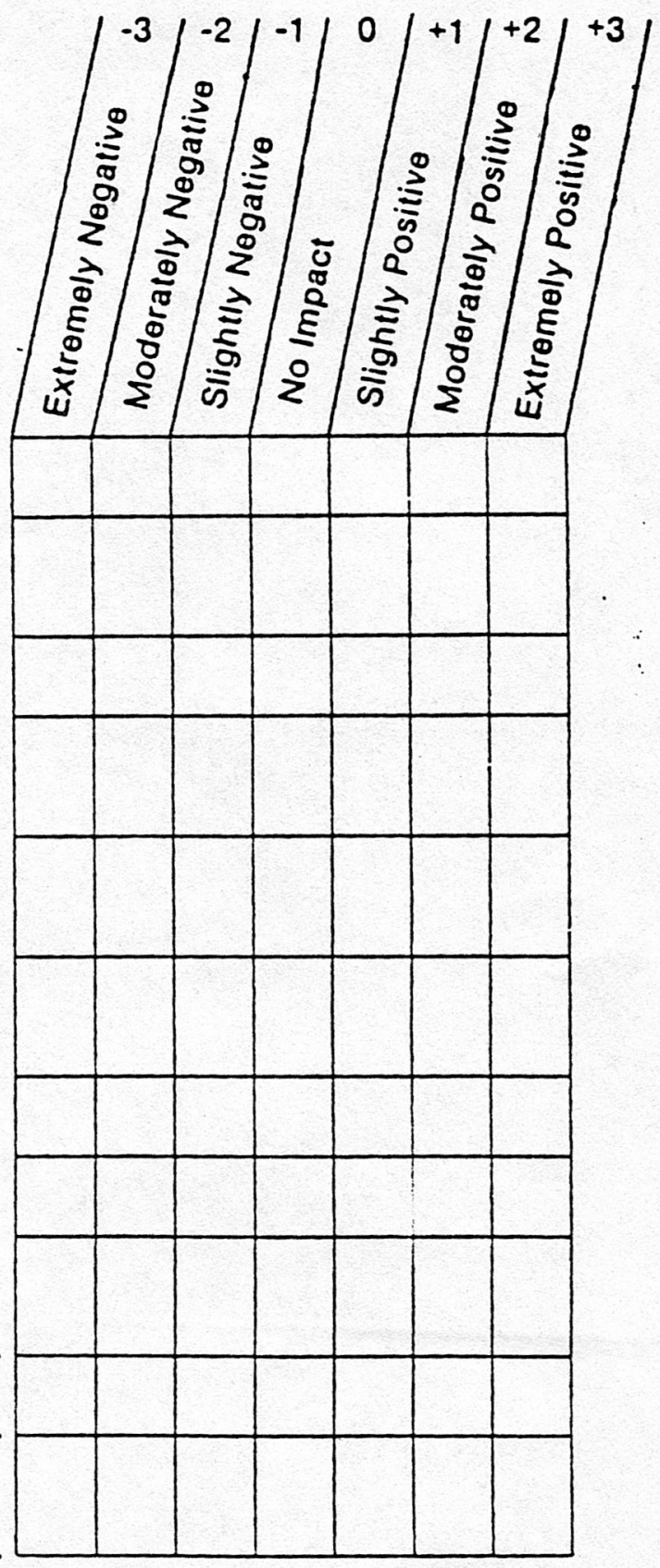


Appendix B

Sample Items

1. What is the highest educational level you have completed?

1 Eight grades or less

2 Some high school

3 High school graduate

4 Some college or specialized school above high school

5 College graduate

6 Some postgraduate work

7 Graduate degree (M.A.,M.S.,M.D.,Ph.D., L.L.D.,etc.)

2. What is your approximate gross yearly income?

1 Less than 5,000 a year

$2 \$ 5,000$ - $\$ 9,9999$ a year

$3 \$ 10,000$ - $\$ 14,999$ a year

$4 \$ 15,000$ - $\$ 19,999$ a year

$5 \$ 20,000-24,999$ a year

$6 \$ 25,000-29,999$ a year

$7 \$ 30,000$ or more a year

3. If you are married, what is your spouse's income?

1 Less than 5,000 a year

$2 \$ 5,000-\$ 9,9999$ a year

$3 \$ 10,000$ - $\$ 14,999$ a year

$4 \$ 15,000-\$ 19,999$ a year
$5 \$ 20,000-24,999$ a year

$6 \$ 25,000-29,999$ a year

$7 \$ 30,000$ or more a year

4. How many years have/had you been smoking cigarettes regularly? (exclude periods of time when you had quit.)

5. During the period when you were smoking the most, about how many cigarettes a day did you usually smoke?

6. If you smoke daily, on the average, how many cigarettes do you now smoke?

7. If you do not smoke daily on the average, how many cigarettes do you now smoke each week?

8. To the best of your knowledge, describe the present use of cigarettes by the people in your life listed below. Use the following al ternatives:

$1=$ does not smoke cigarettes

2 = smokes an occasional cigarette, but less than 5 a day

$3=$ smokes 5 to 10 cigarettes a day

$4=$ smokes 11 to 20 ciagrettes a day

5 = smokes 21 or more cigarettes a day

$6=$ not applicable

Your spouse.

Your best friend of the same sex

Your best friend of the opposite sex... 
9. Since you started smoking cigarettes, how many times have you tried to stop?

1. Never

2. Once

3. Twice

4. Three times

5. Four times
6. Five times

7. Six to ten times

8. El even to twenty-five times

9. More than twenty-five times

10. What problems, if any, did you experience while trying to quit? (Check all that apply):
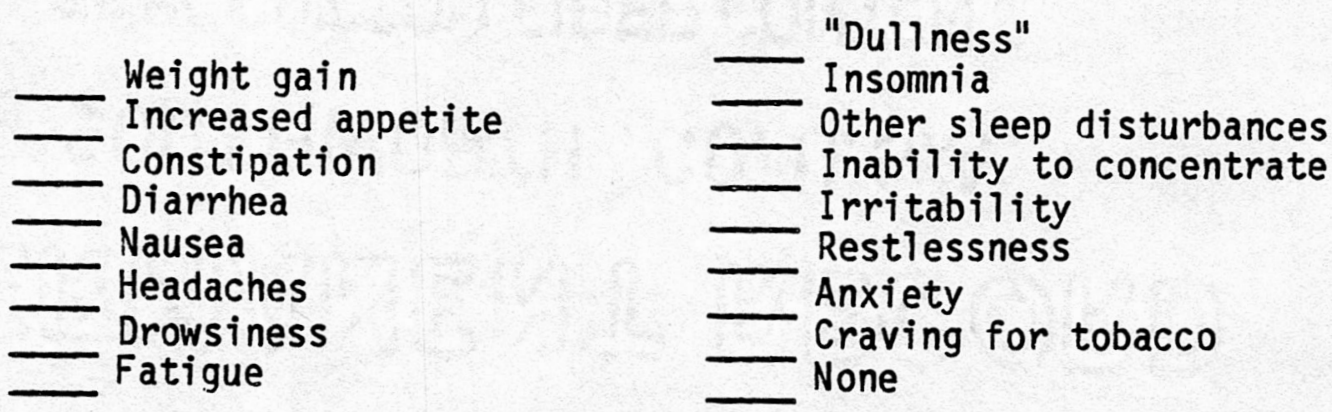

11. 1. I used to smoke cigarettes regularly, but quit at least six months ago.

2. I used to smoke cigarettes regularly, but quit between three and six months ago.

3. I used to smoke cigarettes regularly, but quit less than three months ago.

4. I smoke cigarettes now, but have tried at least once in the past year to quit smoking.

5. I smoke cigarettes now, and have not tried to quit smoking in the past year. In addition, I have no plans to try to quit in the next year.

6. I smoke cigarettes now, and have not tried to quit smoking in the past year. However, I am seriously thinking about quitting in the next year.

12. Here are some statements made by people to describe what they got out of smoking cigarettes. Recall the last six months during the time you smoked. Answer each question in terms of how of ten you felt this way when smoking.

A. I smoked cigarettes in order to keep myself from slowing down.

B. Handling a cigarette has been part of the enjoyment of smoking.

C. Smoking cigarettes has been pleasant and relaxing.

D. I have lit up a cigarette when I felt angry about something. 
E. If I should run out of cigarettes, I would find it almost unbearable until I get them.

F. I have smoked cigarettes automatically without even being aware of it.

G. I have smoked cigarettes to stimulate me, to perk myself up.

H. Part of the enjoyment of smoking a cigarette has come from the steps I have taken to light up.

I. I have found cigarettes pleasurable.

J. When I have felt uncomfortable or upset about something, I have lit up a cigarette.

K. I have been very much aware of the fact when I was not smoking a cigarette.

L. I have lit up a cigarette without realizing I still had one burning in the ashtray.

M. I have smoked cigarettes to give me a "lift".

N. When I have smoked a cigarette, part of the enjoyment has been watching the smoke as I exhale it.

0. I have wanted a cigarette most when I was comfortable and relaxed.

P. When I had been feeling "blue" or wanting to take my mind off cares and worries, I smoked cigarettes.

Q. I would get a real gnawing hunger for a cigarette when I hadn't smoked for a while.

R. I have found a cigarette in my mouth and not remembered putting it there.

13. Has a doctor ever told you that you had any of the following conditions? If YES, do you still have it?
a. Asthma
h. Other cancer
b. Hay fever
i. Heart attack
c. Chronic sinusitis
j. Chest pain (angina)
d. Chronic bronchitis
k. Heart disease
(all kinds)
e. Emphysema
1. High blood pressure
f. Chronic obstructive pulmonary disease
m. Hardening of the arteries
n. Ulcers 


\section{THE LIFE EXPERIENCES SURVEY}

Listed below are a number of events which sometlmes bring about change in the llves of those who experlence them. To the left of the numbered liems, please check those events which you have experlenced In the past six month.

For each item you check, please Indlcate the extent to which you view the event as having elther a positive or negatlve Impact on your life at the llme the event occurred. Check the appropriate column on the right slde of the page. If it had no impact, check the middle column (0).

Occurred in past 6 months

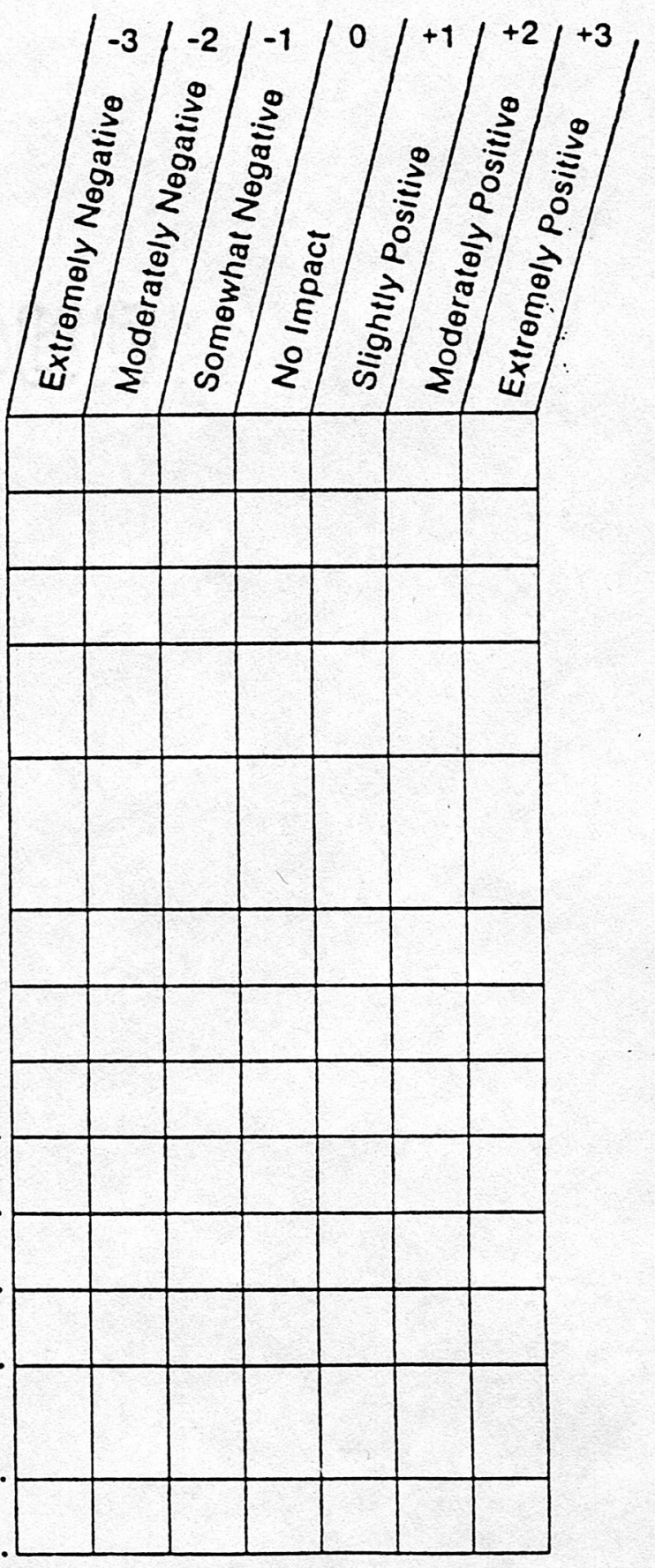

7. Foreclosure on mortgage or loan 
Occured in past 6 months

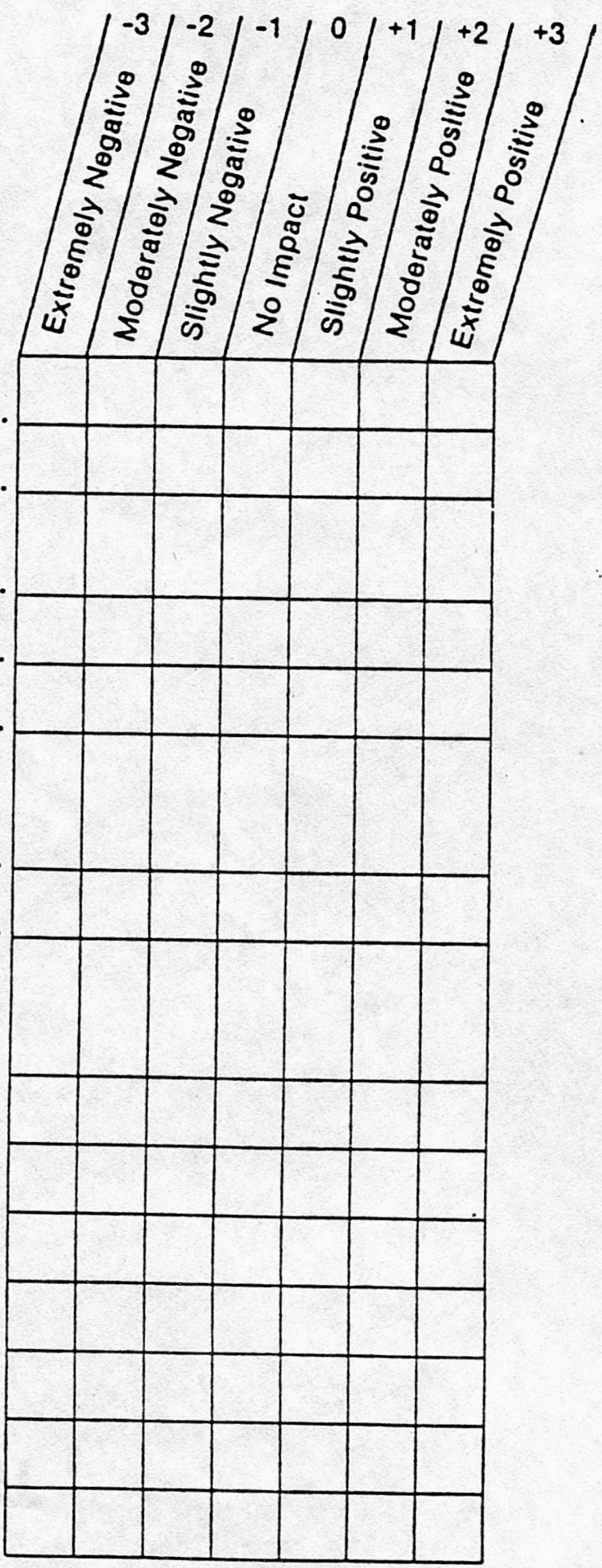


Occurred in past 6 months

16. Se\%ual difficulties

17. Tre uble with employer (in danger of losing job, being suspended, demoted, etc.)

18. Treuble with in-laws

19. Mz or change in financial status (a lot better off or a lo: torse off)

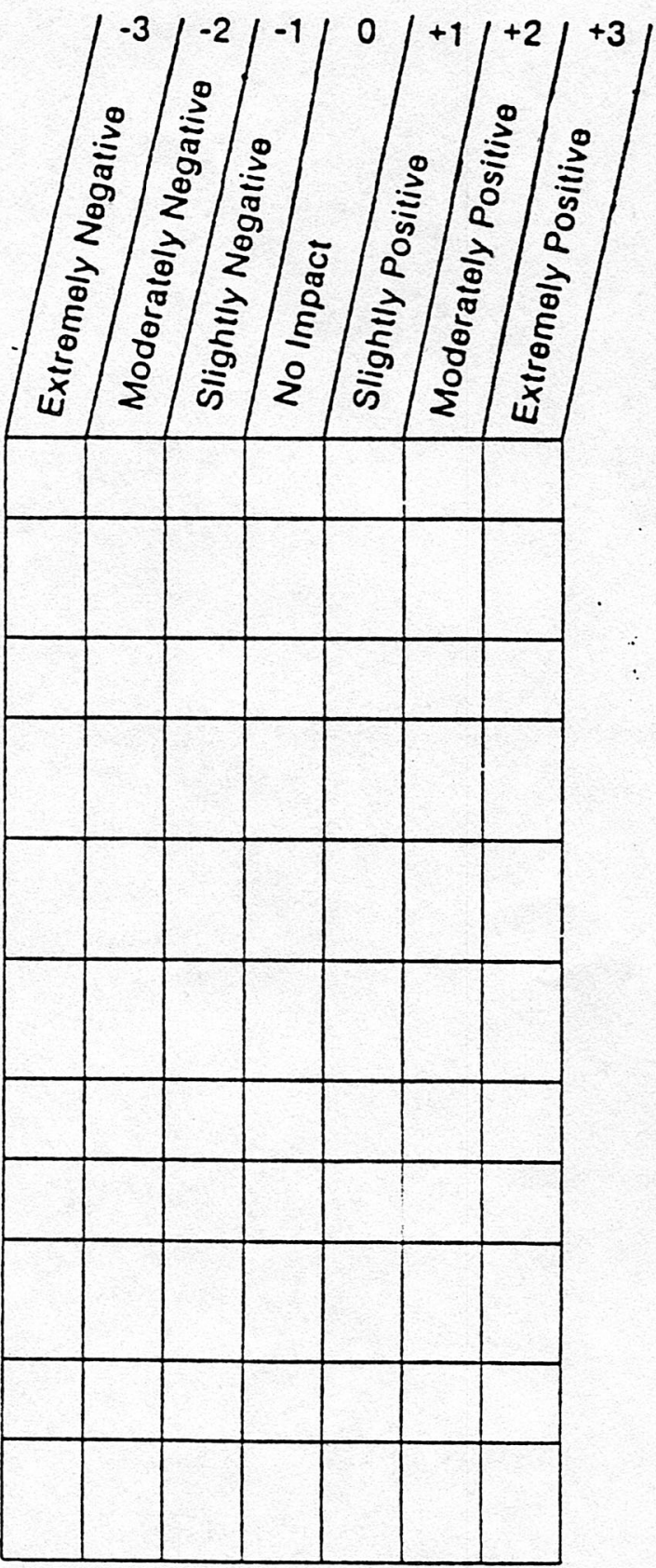


Occurred in past 6 months

27. Married Male: Change in wife's work outside the home (beginning work, changing to a new job, etc.)

28. Married Female: Change in husband's work (loss of job, beginning new job, retirement, etc.)

29. Major change in usual type and/or amount of recreation

30. Borrowing more than $\$ 10,000$ (buying home, business, etc.)

31. Borrowing less than $\$ 10,000$ (buying car, TV, getting school loan, etc)

32. Being fired from job

33. Male: Wife/girlfriend having abortion

34. Female: Having abortion

35. Major personal illness or injury

36. Major change in social activities, e.g. parties, movies, visiting (increased or decreased participation)

37. Major change in living conditions of family (building new home, remodeling, deterioration of home, neighborhood, etc.)

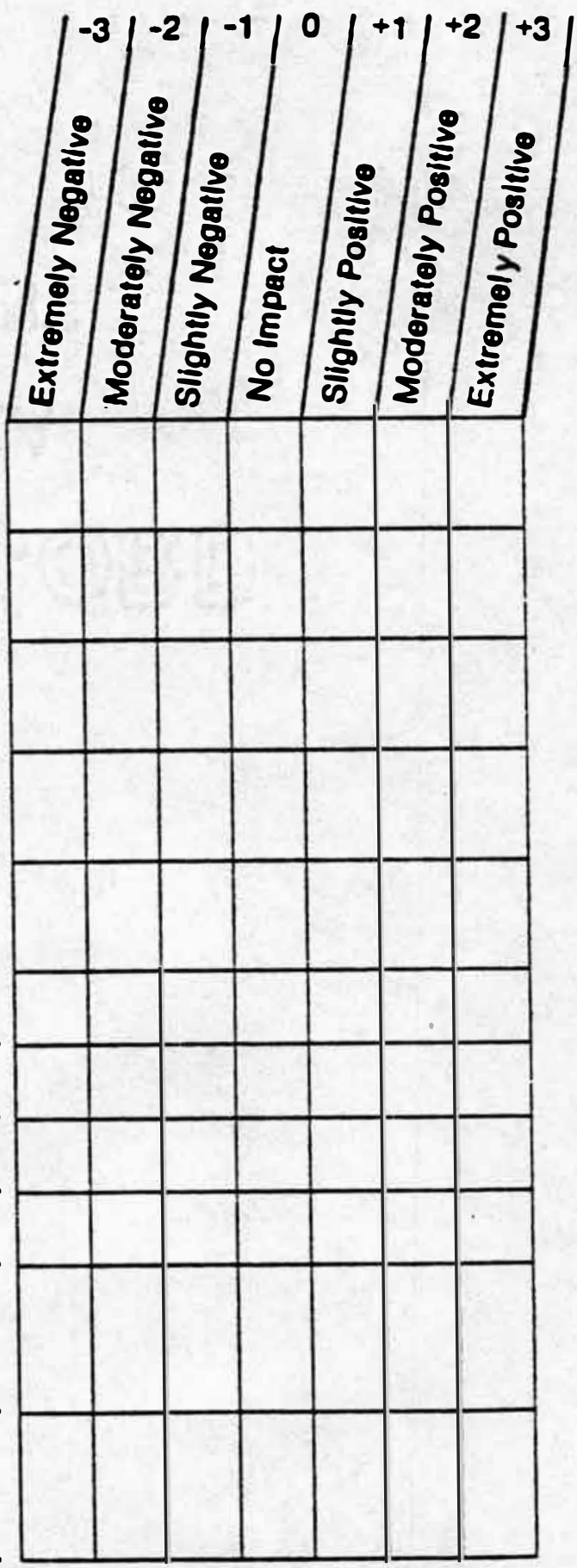


Occurred in past 6 months

38. Divorce

39. Serious injury or illness of close friend

40. Retirement from work

41. Son or daughter leaving home (due to marriage, college, etc.)

42. Ending of formal schooling

$\square$

43. Separating from spouse (due to work, travel, etc.)

44. Engagement

45. Breaking up with boyfriend/girifriend

46. Leaving home for the first time

47. Reconciliation with boyfriend/girlfriend

Other recent experiences which have had an impact on your life. List and rate.

48.

49.

50.

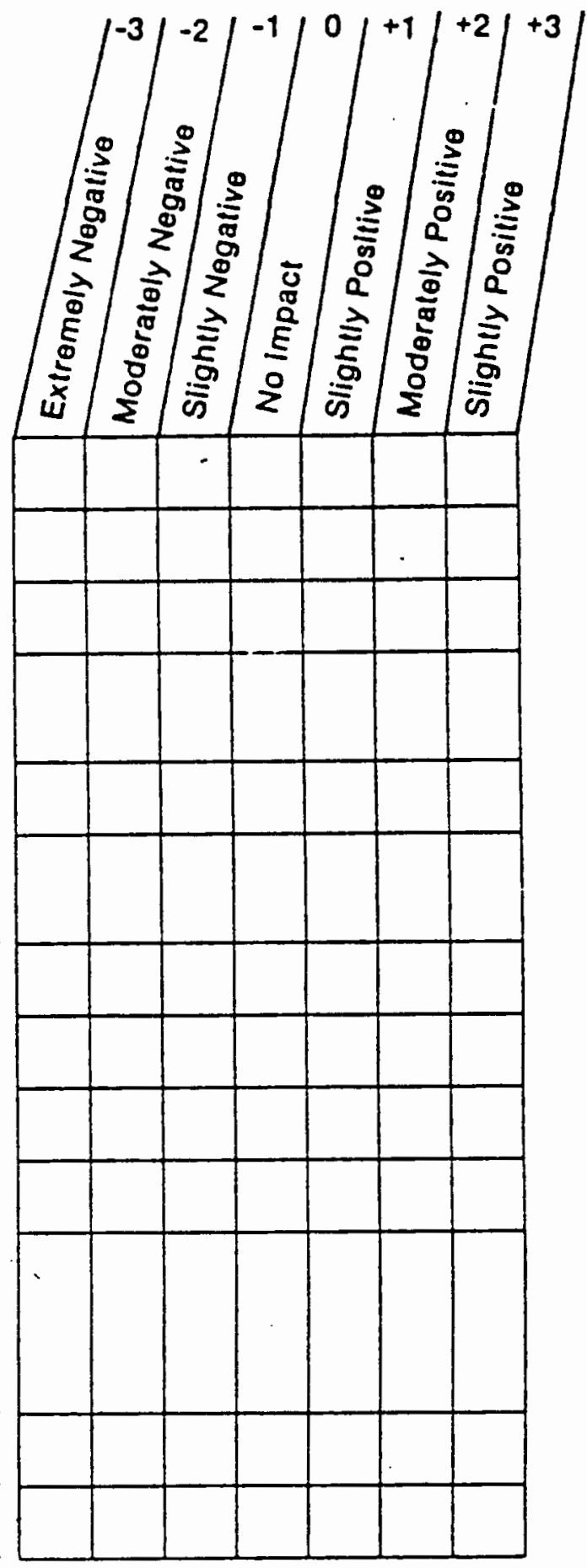

(You've answered a lot of questions; this might be a good time to take a break if you have not already done so.) 
Appendix C

Discriminant Analysis Results

\begin{tabular}{ccccc}
\hline Group & Eigenvalue & Bartlett's V & df & $p$ \\
\hline Immotives & .32976 & 23.227376 & 3 & $<.001$ \\
Relapsers & .17471 & 31.890051 & 6 & $<.001$ \\
\hline
\end{tabular}


Appendix D

Analysis of Variance Summary Table for Previous Quits (Round I Immotives)

\begin{tabular}{lrcccc}
\hline Source & d.f. & Sum of Squares & Mean Squares & $F$ ratio & $p$ \\
\hline Between groups & 1 & 24.1904 & 24.1904 & 7.47 & p \\
Within groups & 83 & 268.7974 & 3.2385 & & \\
Total & 84 & 292.9875 & & &
\end{tabular}


Appendix E

Analysis of Variance Surmary Table for Pleasure (Round I Immotives)

\begin{tabular}{lccccc}
\hline Source & d.f. & Sum of Squares & Mean Squares & F ratio & $p$ \\
\hline Between groups & 1 & 53.9803 & 53.9803 & 14.936 & 2.001 \\
Within groups & 83 & 299.9728 & 3.6141 & & \\
Total & 84 & 353.9529 & & & \\
\end{tabular}


Appendix $F$

Analysis of Variance Sunmary Table for Education (Round I Relapsers)

\begin{tabular}{lccccc}
\hline Source & d.f. & Sum of Squares & Mean Squares & F ratio & p \\
\hline Between groups & 3 & 22.3534 & 7.4511 & 4.137 & $<.001$ \\
Within groups & 191 & 344.0251 & 1.8012 & & \\
Tota 1 & 194 & 366.3784 & & \\
\end{tabular}


Appendix G

Analysis of Variance Summary Table for Daily Cigarettes (round I Relapsers)

\begin{tabular}{lccccc}
\hline Source & d.f. & Sum of Squares & Mean Squares & $F$ ratio & $p$ \\
\hline Between groups & 3 & 3274.0543 & 1091.3513 & 7.070 & $<.001$ \\
Within Groups & 191 & 29485.0959 & 154.3722 & & \\
Total & 194 & 32759.1484 & & & \\
\hline
\end{tabular}




\section{Appendix H}

Newman-Keuls Comparisons on Education for Round I Relapsers

Immotives Contemplators Relapsers Recent Quitters

Group

Means

\subsection{3}

4.41

4.52

4.63

$-98^{*}$

$1.11 *$

$1.20 *$

-

.11

.22

.11 


\section{Appendix I}

Newman-Keuls Comparisons on Daily Cigarettes for Round I Relapsers

\begin{tabular}{lcccc}
\hline Group & Relapsers & Recent Quitters & Immotives & Complemplators \\
Means & 22.37 & 22.94 & 30.29 & 31.80 \\
& & .57 & 7.92 & 9.43 \\
& - & 7.35 & 8.86 \\
& & - &
\end{tabular}

